\title{
Effects of long term inhaled high dose beclomethasone dipropionate on adrenal function
}

\author{
MJ SMITH, ME HODSON
}

\section{From the Cardiothoracic Institute, Brompton Hospital, London}

ABSTRACT Studies of adrenal function were performed on 54 asthmatic patients who were taking long term high doses of inhaled beclomethasone dipropionate ranging from 500 to $2000 \mu \mathrm{g} / \mathrm{day}$ for between six and 60 months. Of the 43 patients taking up to $1500 \mu \mathrm{g} /$ day, $39(91 \%)$ had normal basal plasma cortisol concentrations and normal short tetracosactrin responses and 24 hour urinary free cortisol excretion was within the normal range in eight of nine patients tested. Some evidence of adrenal suppression was found in patients taking $2000 \mu \mathrm{g} / \mathrm{day}$, with basal plasma cortisol below the normal range in four out of 11 patients and 24 hour urinary free cortisol excretion below the normal range in five out of six patients tested. Only one of the 11 patients taking $2000 \mu \mathrm{g} /$ day had a short tetracosactrin response below the normal range: the mean rise in plasma cortisol was, however, significantly lower in this group than in those taking $1000 \mu \mathrm{g} /$ day (328 (SE 30) and 506 (34) nmol/1 respectively) (p < 0.01). Patients taking more than $1500 \mu \mathrm{g} /$ day of inhaled beclomethasone may require systemic corticosteroids during prolonged stress.

High dose inhaled beclomethasone dipropionate has been shown to be effective in improving asthma control and reducing oral steroid requirements in many asthmatic patients who are not satisfactorily controlled with conventional doses of beclomethasone dipropionate $(400-800 \mu \mathrm{g} /$ day $) .^{1-3}$

The main potential advantage of inhaled corticosteroid treatment lies in the lack of systemic side effects; thus knowledge of the effects of higher doses of beclomethasone dipropionate on adrenal function is crucial. Studies of adrenal function performed on small numbers of healthy adult volunteers showed no evidence of adrenal suppression when $1 \mathrm{mg} /$ day of inhaled beclomethasone dipropionate was taken for 28 days $^{4}$; one of the three normal individuals, however, developed a low plasma cortisol concentration after one week on $2 \mathrm{mg} /$ day. In subsequent dose response studies the same author reported that inhaled beclomethasone dipropionate had no effect on morning plasma cortisol concentrations until a daily dose of $3 \mathrm{mg}$ was reached. ${ }^{5}$ The effects of inhaled beclomethasone dipropionate on adrenal function in asthmatic patients when taken in doses above $1 \mathrm{mg} /$ day are uncertain. Clark ${ }^{6}$ states that at

Address for reprint requests: Dr MJ Smjth, Cardiothoracic Institute, Brompton Hospital, London SW3 6HP.

Accepted 16 May 1983 doses of 1.5 to $2.0 \mathrm{mg} /$ day systemic activity becomes increasingly evident; and Gaddie et al $^{7}$ showed a slight reduction in basal plasma cortisol concentrations at $1600 \mu \mathrm{g} /$ day but this was not considered significant. Other studies have shown no evidence of adrenal suppression at doses of up to $2 \mathrm{mg} /$ day. ${ }^{38}$

In this study we investigated the effects of long term inhaled high dose beclomethasone dipropionate on adrenal function in asthmatic patients who were not taking oral corticosteroids.

\section{Methods}

Studies of adrenal function were performed on a total of 54 asthmatic patients who were taking inhaled beclomethasone dipropionate in doses rang- 은 ing from 500 to $2000 \mu \mathrm{g} /$ day, the steroid being administered via an inhaler delivering $250 \mu \mathrm{g}$ of beclomethasone dipropionate in each metered dose $N$ (BDP 250). The mean duration of treatment before testing was 23 months (range 6-60 months). The 0 mean age of the patients was 53 years (range 17-76 $\mathrm{\omega}$ years), and there were equal numbers of men and women. None of these patients was receiving con- $\theta$ current oral corticosteroid treatment. Eight patients $\mathbb{D}$ had a history of continuous oral steroid treatment of $\stackrel{\mathscr{P}}{\rightarrow}$ at least one year's duration (mean seven years, $\underset{T}{0}$ range 1-15 years). One of them had been having oral steroid treatment until 12 months before test- 
ing, while the remaining seven had stopped treatment at least 18 months previously (range 18-48 months). Twenty six patients had received short courses of oral steroids during the year preceding the test but none within the last six months. The remaining 20 patients had never received oral steroid treatment. Blood samples for estimation of basal plasma cortisol concentrations were taken between 9 and 10 am and short tetracosactrin stimulation tests were performed on all patients, blood samples for plasma cortisol estimation being taken immediately before and 30 minutes after intramuscular injection of $0.25 \mathrm{mg}$ of tetracosactrin. Fifteen of these patients underwent more detailed study, with measurement of diurnal plasma cortisol concentration at 9 am and 12 midnight and 24 hour urinary free cortisol estimation. All cortisol assays were performed by direct immunoassay with a cortisol radioimmunoassay kit (Amersham).

The results were analysed according to total daily dose of beclomethasone dipropionate, and the effects of age, previous oral steroid treatment, dose frequency, and duration of high dose beclomethasone dipropionate on adrenal function were assessed. The group values given are means with standard errors in parenthesis.

\section{Results}

\section{BASAL PLASMA CORTISOL ESTIMATION}

In 48 of the 54 patients basal plasma cortisol concentrations were within our laboratory normal range (165-700 nmol/l), as shown for four dose levels in figure 1 ( 51 patients). The mean value for the 28 patients taking $1000 \mu \mathrm{g} /$ day of beclomethasone dipropionate was 410 (32) $\mathrm{nmol} / \mathrm{l}$, which is not significantly different from the control mean of 432 $\mathrm{nmol} / \mathrm{l}$. The mean for the 11 patients taking 2000 $\mu \mathrm{g} /$ day was 207 (31) $\mathrm{nmol} / \mathrm{l}$, which is significantly lower than for the group taking $1000 \mu \mathrm{g} /$ day ( $\mathrm{p}<$ 0.01 ), although it is still within the normal range for our laboratory. There were six patients with low basal plasma cortisol concentrations. Two of these were taking $1000 \mu \mathrm{g} /$ day of beclomethasone dipropionate and four $2000 \mu \mathrm{g} / \mathrm{day}$.

\section{SHORT TETRACOSACTRIN STIMULATION TESTS}

Fifty one of the 54 patients tested had 30 minute tetracosactrin responses within the normal range, defined in our laboratory as a rise in plasma cortisol concentration of over $190 \mathrm{nmol} / \mathrm{l} 30$ minutes after intramuscular injection of $0.25 \mathrm{mg}$ of tetracosactrin. The responses at dose levels of 1000 and $2000 \mu \mathrm{g} /$ day are shown in figure 2 (39 patients). The mean value for rise in plasma cortisol for the 11 patients taking $2000 \mu \mathrm{g} /$ day of beclomethasone

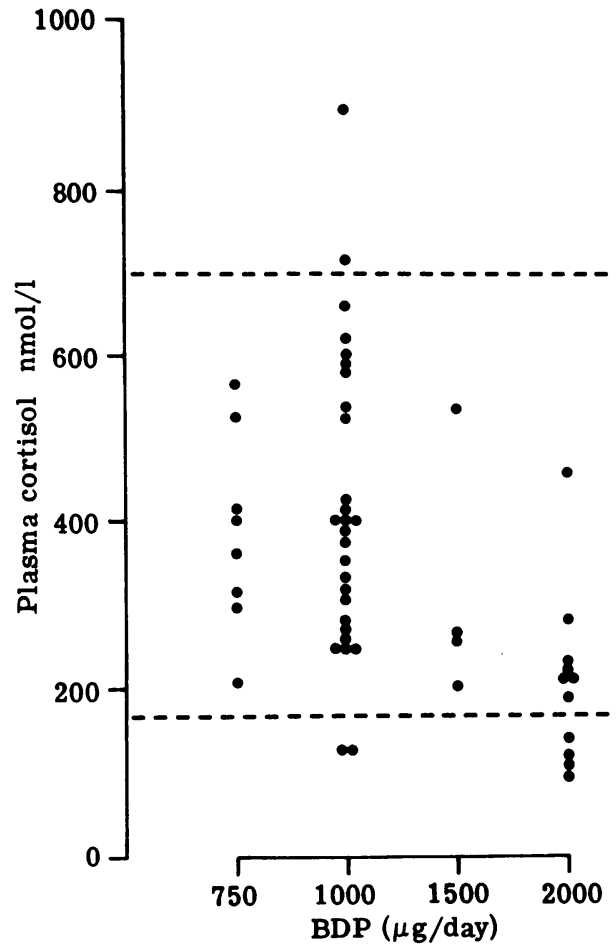

Fig 1 Basal plasma cortisol concentrations at four dose levels of beclomethasone dipropionate (BDP) (samples taken between 9 and $10 \mathrm{am}$ ). The broken lines indicate the normal range, 165-700 nmolll (mean $\pm 2 S D$ ).

Conversion: SI to traditional units-Cortisol: 1 nmolll = $36.2 \mathrm{ng} / 100 \mathrm{ml}$.

dipropionate-328 (30) $\mathrm{nmol} / \mathrm{l}$-was significantly lower than the mean for 28 patients taking 1000 $\mu \mathrm{g} /$ day-506 (34) nmol/l ( $<<0.01)$.

Two patients in the group taking $1000 \mu \mathrm{g} /$ day had abnormal tetracosactrin responses. One of these patients had been having continuous oral corticosteroid treatment for eight years; it was withdrawn 12 months before adrenal function was assessed. The meaning of the abnormal response in the second patient is uncertain as her initial basal plasma cortisol concentration was above our normal range and she is now undergoing further investigation to exclude endogenous Cushing's syndrome. The two patients with low plasma cortisol concentrations who were taking $1000 \mu \mathrm{g} /$ day of beclomethasone dipropionate had very good $\mathbf{3 0}$ minute responses to tetracosactrin (increases in plasma cortisol of 715 $\mathrm{nmol} / \mathrm{l}$ and $615 \mathrm{nmol} / \mathrm{l}$ ), whereas the four patients with low plasma cortisol concentrations who were taking $2000 \mu \mathrm{g} /$ day had significantly lower responses (mean increase $364(39) \mathrm{nmol} / \mathrm{l})(\mathrm{p}<$ $0 \cdot 02)$.

The mean plasma cortisol concentrations after 


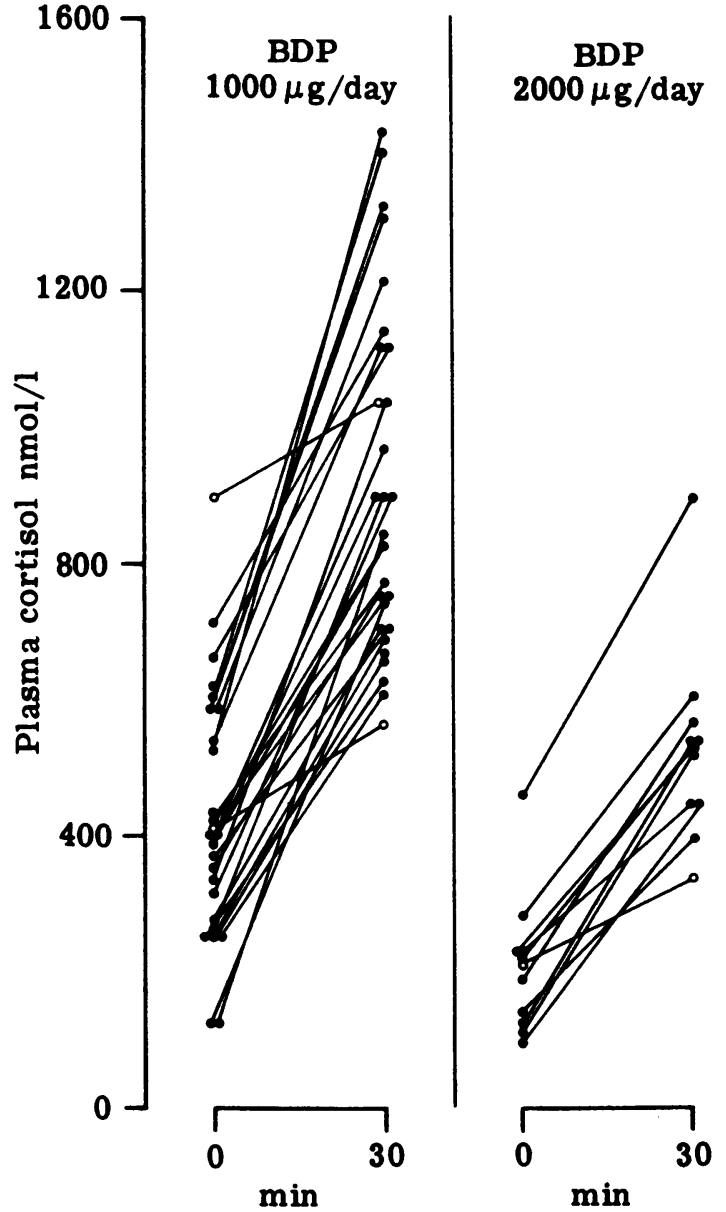

Fig 2 Short tetracosactrin responses of patients taking 1000 and $2000 \mu \mathrm{g} /$ day of beclomethasone dipropionate. $(B D P)$. — normal response to tetracosactrin; reduced response to tetracosactrin. Conversion: SI to traditional units - Cortisol: $1 \mathrm{nmol} / \mathrm{l}=36 \cdot 2 \mathrm{ng} / 100 \mathrm{ml}$.

tetracosactrin of the patients taking $1000 \mu \mathrm{g} /$ day (28 patients) and $1500 \mu \mathrm{g} /$ day (four patients) were not significantly different, being 915 (48) $\mathrm{nmol} / \mathrm{l}$ and 878 (105) nmol/l respectively. The mean for the 11 patients taking $2000 \mu \mathrm{g} /$ day was $534(45) \mathrm{nmol} / \mathrm{l}$, which is significantly lower than both the other groups ( $p<0.01$ ). Four of these 11 patients had peak values of less than $500 \mathrm{nmol} / \mathrm{l}$.

\section{DIURNAL VARIATION}

All the 15 patients tested showed a significant diurnal variation in plasma cortisol concentration, the mean value for the midnight concentration (59 (11) nmol/l) being lower than that for the 9 am concentration $(309(33) \mathrm{nmol} / \mathrm{l})(\mathrm{p}<0.001)$. Significant simple correlations were found to exist between individual patients' midnight and basal plasma cortisol concentrations $(r=0.56, p=0.02)$ and the midnight plasma cortisol concentration and short tetracosactrin response $(r=0.62, p<0.01)$, but there was no correlation between 24 hour urinary free cortisol excretion and midnight plasma cortisol concentration.

TWENTY-FOUR HOUR URINARY FREE CORTISOL EXCRETION

Twenty four hour urinary free cortisol excretion was studied in 15 patients who were taking 1000 to 2000 $\mu \mathrm{g} /$ day of beclomethasone dipropionate. The mean 24 hour excretion for the seven patients taking 1000 $\mu \mathrm{g} /$ day was 115 (12) $\mathrm{nmol} / 24 \mathrm{~h}$, which is significantly lower than the control mean of 210 (10) $n m o l / 24 h(p<0.01)$. Six of these seven patients, however, had values within the normal range quoted for the cortisol radioimmunoassay kit $(90-330$ nmol/24 h) (fig 3). The single patient at this dose level who had a low cortisol excretion was the

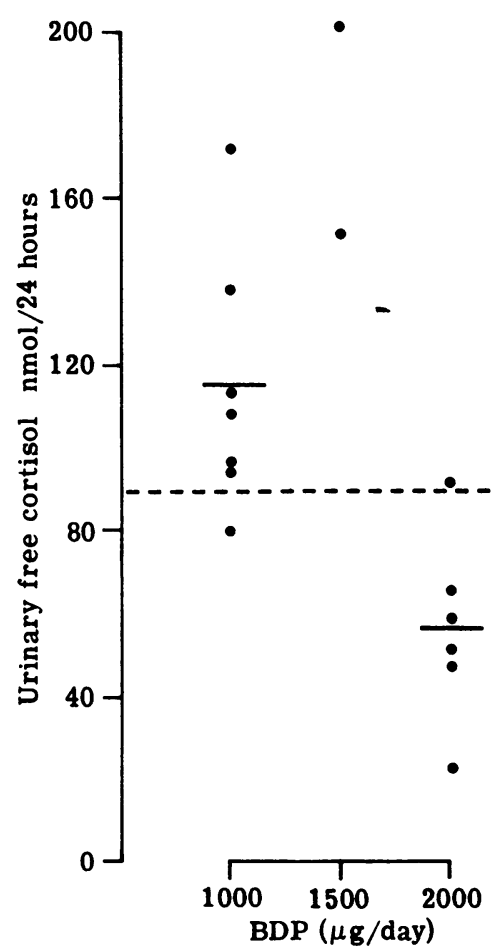

Fig 3 Twenty-four hour urinary free cortisol excretion in patients taking 1000, 1500, and $2000 \mu \mathrm{g} /$ day of beclomethasone dipropionate (BDP). The broken line indicates the lower limit of normal range, $90 \mathrm{nmol} / 24 \mathrm{~h}$. Conversion: SI to traditional units - Cortisol: 1 nmolll = $36 \cdot 2 \mathrm{ng} / 100 . \mathrm{ml}$. 
Comparison of mean basal plasma cortisol and plasma cortisol response to tetracosactrin in relation to previous oral steroid treatment

\begin{tabular}{|c|c|c|c|}
\hline \multirow[t]{2}{*}{ Oral steroid history } & \multirow[t]{2}{*}{ No of patients } & \multicolumn{2}{|c|}{ Mean (SEM) plasma cortisol (nmolll) } \\
\hline & & Basal & $\begin{array}{l}\text { Increase after } \\
\text { tetracosactrin }\end{array}$ \\
\hline Previous long term oral steroids & 8 & $\Gamma_{S} 371(49)$ & $\begin{array}{r}385 \text { (46) } 7 \\
\text { NS }\end{array}$ \\
\hline Intermittent short courses & 26 & $\begin{array}{l}=305(29) \\
<0.02\end{array}$ & $493(40) \frac{1}{N S}$ \\
\hline No oral steroids & 20 & L $447(46)$ & $461(36)\rfloor\rfloor$ \\
\hline
\end{tabular}

NS-not significant.

Conversion: SI to traditional units - Cortisol: $1 \mathrm{nmol} / \mathrm{l}=36 \cdot 2 \mathrm{ng} / 100 \mathrm{ml}$.

patient already mentioned who had an abnormal tetracosactrin response and who had received oral corticosteroid treatment until 12 months before the date of the study.

Two patients taking $1500 \mu \mathrm{g} /$ day were studied and both had values within the normal range. Both these patients were taking two puffs of beclomethasone dipropionate three times daily, whereas the other 13 patients followed regimens requiring treatment to be taken four times daily (one or two puffs on each occasion).

Five of the six patients taking $2000 \mu \mathrm{g} /$ day had a 24 hour urinary free cortisol excretion below the normal range. Only one of the five had received oral corticosteroids in the past ( 12 months previously). The mean value of 57 (9) $\mathrm{nmol} / 24 \mathrm{~h}$ was significantly lower than the mean value of 115 (12) $\mathrm{nmol} / 24 \mathrm{~h}$ in the group taking $1000 \mu \mathrm{g}$ /day ( $\mathrm{p}<$ $0 \cdot 01$ ).

\section{EFFECTS OF PREVIOUS ORAL STEROID}

\section{TREATMENT ON ADRENAL FUNCTION}

Patients were divided into those who had received long term continuous oral steroids, those who had received intermittent short courses, and those who had never received oral steroids (table). There was no significant difference in mean basal plasma cortisol concentration between the group who had previously taken long term oral steroids and either of the other two groups. There was, however, a significantly lower mean basal plasma cortisol concentration in the group who had taken intermittent steroids than in those who had received no steroid ( $p$ $<0.02$ ). This difference is almost certainly due to a higher proportion of patients in the former group who were taking $2000 \mu \mathrm{g}$ of beclomethasone dipropionate a day ( $31 \%$ compared with $5 \%$ ). Some of the patients in the group who had had intermittent steroids, however, had received a short course of prednisolone six to 12 months before testing. The patients who had previously had long term oral steroids tended to have smaller rises in plasma cortisol after tetracosactrin than the other two groups but the differences between the means are not significant.

Of the 15 patients who had 24 hour urinary free cortisol excretion measured, two had received a short course of prednisolone in the year before testing (six and eight months previously) - they had been taking $1500 \mu \mathrm{g}$ of beclomethasone dipropionate a day and in both all indices of adrenal function were within the normal range.

\section{EFFECTS OF AGE, DURATION OF HIGH DOSE} BECLOMETHASONE DIPROPIONATE TREATMENT, AND DOSE FREQUENCY

There was no correlation between basal plasma cortisol concentration or tetracosactrin response and either age or duration of high dose beclomethasone dipropionate treatment. Analysis of urinary free cortisol excretion showed significant simple correlations with dose $(r=0.5475, p<0.025)$, age $(r=$ $0.7270, p<0.005)$, and dose frequency $(r=$ $0.6316, p<0.01$ ). Multiple regression analysis of these data showed the strongest correlation between urinary free cortisol excretion and dose combined with frequency $\left(\mathrm{r}^{2}=0.7187, \mathrm{p}<0.001\right)$ and nothing is gained by including the variable of age.

\section{Discussion}

Beclomethasone dipropionate has been shown to possess high topical anti-inflammatory activity with relatively modest oral systemic glucocorticoid activity ${ }^{4}$ and it is thus eminently suitable for the treatment of asthma by inhalation. Most studies have shown no significant effect on adrenal function at standard doses of 400 to $800 \mu \mathrm{g} /$ day, ${ }^{357}$ although a conflicting report by Weinberger et $a^{9}$ showed reduced 24 hour urinary free cortisol excretion in a small group of children taking $400 \mu \mathrm{g} / \mathrm{day}$.

At doses of up to $1500 \mu \mathrm{g} /$ day of inhaled bec- 
lomethasone dipropionate 39 patients $(91 \%)$ had basal plasma cortisol concentrations and short tetracosactrin responses within the normal range, and 24 hour urinary free cortisol excretion was within the normal range in eight of nine patients tested. Two patients taking $1000 \mu \mathrm{g} /$ day had low basal plasma cortisol concentrations but both had normal responses to tetracosactrin. At $2000 \mu \mathrm{g} /$ day, however, there was evidence of adrenal hypofunction with reduced 24 hour urinary free cortisol excretion in five out of six patients and low basal plasma cortisol levels in four of 11 patients. The finding of plasma cortisol levels of under $500 \mathrm{nmol} / \mathrm{l}$ after tetracosactrin in four of the patients taking $2000 \mu \mathrm{g} /$ day might be regarded by some workers as further evidence of adrenal hypofunction. ${ }^{10}$ The single patient taking $2000 \mu \mathrm{g} /$ day who had an abnormal tetracosactrin response had been taking long term oral corticosteroids until 12 months previously and was the only one to show reduction in all three indices of adrenal function. Since it has been shown that impairment of adrenal reserve after suppression of adrenal function by corticosteroid treatment may persist even one year after cessation of treatment, ${ }^{11}$ there could be some residual effect from oral treatment in this patient. There were six patients in the group taking $1000 \mu \mathrm{g} /$ day who had received regular oral corticosteroids two to four years previously and all had completely normal adrenal function tests.

In this study we have investigated basal adrenal function, short term response of the adrenal cortex to tetracosactrin stimulation, and basal 24 hour urinary free cortisol excretion. We did not undertake to test the reserve of the hypothalamic pituitary axis in response to stress using, for example, the insulin tolerance test, which is at present perhaps the most widely used test of the function of the hypothalamic pituitary axis. In a comparative study, however, Lindholm et $a l^{10}$ showed that the 30 minute adrenocorticotrophic hormone test accurately reflects the function of the hypothalamic pituitary axis as assessed by the insulin tolerance test. Having shown normal basal adrenal function and short term reserve in most of these patients but reduced 24 hour urinary free cortisol excretion in those taking $2000 \mu \mathrm{g}$ of beclomethasone dipropionate a day we are concerned about hypothalamic pituitary axis reserve in times of prolonged stress in this latter group of patients. The normal ranges quoted in this type of study are representative of a normal, healthy population and values lying outside these ranges can be said to be abnormal. The normal ranges are somewhat arbitrary and do not allow us to predict the likelihood that a patient with low values will develop acute adrenal insufficiency. There is very little evidence to favour one test or another for assessing long term hypothalamic pituitary axis reserve and predicting an individual patient's response to illness or stress. During the six years in which high dose beclomethasone has been used in our hospital we know of no documented episodes of acute adrenal insufficiency related to its use. Spitzer et al $^{12}$ showed that when asthmatic patients with evidence of severe adrenal suppression while taking regular oral steroids were transferred to $400 \mu \mathrm{g} /$ day of beclomethasone dipropionate the short term responses of plasma cortisol to tetracosactrin and insulin stress recovered within six months, whereas the 24 hour urinary excretion of steroids remained low. They suggest that in such patients short term adrenal reserve is intact, but that during prolonged stress, such as infection, trauma, or surgery, additional systemic steroids should be administered. We would recommend that this should be the practice in patients taking the very high doses of inhaled beclomethasone dipropionate; this is particularly relevant in patients who have received regular oral steroid treatment within the last 12 months.

Patients with moderate to severe asthma may gain considerable benefit from using higher than conventional doses of inhaled beclomethasone dipropionate. ${ }^{12}$ From our studies there appears to be very little risk of their developing appreciable adrenal suppression on long term inhaled beclomethasone dipropionate in doses of up to $1500 \mu \mathrm{g} /$ day. In patients requiring higher doses the risks of developing some degree of adrenal suppression should be balanced against the therapeutic advantages and precautions should be taken to provide systemic steroid cover in cases of prolonged stress.

We would like to thank the physicians at the Brompton Hospital for allowing us to study their patients, Mr M Kemp for performing the cortisol assays, Glaxo Pharmaceuticals for financial assistance, Miss M Rehahn for help with statistical analysis, Miss S Hockley for secretarial assistance, and the Augustus Newman Foundation for financial support of MJS.

\section{References}

'Smith MJ, Hodson ME. High dose beclomethasone inhaler in the treatment of asthma. Lancet 1983;i:265-9.

${ }^{2}$ Toogood JH, Lefcoe NM, Haines DSM, Jennings B, Errington H, Baksh L. A graded dose assessment of the efficacy of beclomethasone dipropionate aerosol for severe chronic asthma. J Allergy Clin Immunol 1977;59:298-308.

${ }^{3}$ Costello JF, Clark TJH. Responses of patients receiving high dose beclomethasone dipropionate. Thorax 1974;29:571-3. 
4 Harris DM, Martin LE, Harrison C, Jack D. The effect of oral and inhaled beclomethasone dipropionate on adrenal function. Clin Allergy 1973;3:243-8.

5 Harris DM. Properties and therapeutic uses of some corticosteroids with enhanced topical potency. J Steroid Biochem 1975;6:711-6.

- Clark TJH. Importance of dosage schedules in local steroid treatment for asthma. Folia Allergologica et Immunologica Clinica 1975;22:232.

${ }^{7}$ Gaddie V, Reid IW, Skinner C, Petrie GR, Sinclairm DVM, Palmer KNV. Aerosol beclomethasone dipropionate-a dose response study in chronic bronchial asthma. Lancet 1973;ii:280-1.
${ }^{8}$ Francis RS. High dose beclomethasone aerosol for severe asthma. Br J Dis Chest 1979;73:424 (abstract).

- Weinberger M, Sherman B. Inhaled steroid aerosols and alternate day prednisone. Lancet 1979;i:871-2.

${ }^{10}$ Lindholm J, Kehlet $\mathrm{H}$, Blichert-Toft $\mathrm{M}$, Dinesen B, Riishede J. Reliability of the 30 minute ACTH test in assessing hypothalamic-pituitary-adrenal function. $J$ Clin Endocrinol Metab 1978;47:272-4.

${ }^{11}$ Melby JC. Systemic corticosteroid therapy: pharmacology and endocrinological considerations. Ann Intern Med 1974;81:505-12.

12 Spitzer SA, Kaufman H, Koplovitz A, Topilsky M, Blum I. Beclomethasone dipropionate and chronic asthma. Chest 1976;70:38-42. 